\title{
Evaluasi dan Pengembangan Sistem Manajemen Rantai Pasok Bandeng Segar (Chanos chanos) di Kota Bekasi, Jawa Barat
}

\author{
Evaluation and Development of Supply Chain Management of Fresh Milkfish (Chanos chanos) \\ in the City of Bekasi
}

\author{
Yefni Widria $^{* 1}$, Wini Trilaksani² ${ }^{2}$ dan Eko Ruddy Cahyadi ${ }^{3}$
}

\author{
${ }^{1}$ Kementerian Kelautan dan Perikanan, Ditjen Penguatan Daya Saing Produk Kelautan dan Perikanan \\ Jl. Medan Merdeka Timur No. 16 Gedung Mina Bahari III, Lt. 14 Jakarta 10110 \\ Kotak POS 4130 JKP 10041 Telp. (021) 35100132 Faximile (021) 3500132, 3520844 \\ 2Departemen Teknologi Hasil Perairan, Fakultas Perikanan dan Ilmu Kelautan, IPB \\ Jl. Agatis Kampus IPB Darmaga Bogor 16680 \\ ${ }^{3}$ Departemen Manajemen, Fakultas Ekonomi dan Manajemen, IPB \\ Jl. Kamper Kampus IPB Dramaga Bogor 16680
}

\begin{abstract}
ABSTRAK
Studi kasus dilaksanakan terhadap 12 IKM pengolahan bandeng di Kota Bekasi dengan bahan baku berasal dari Kabupaten Karawang melalui suatu rantai pasok bandeng segar. Potensi Kabupaten Karawang sebagai penghasil bandeng tidak menjamin ketersediaan bahan baku secara berkelanjutan. Tujuan penelitian ini adalah: (1) Mengevaluasi rantai pasok; dan (2) Menyusun strategi prioritas pengembangan sistem manajemen rantai pasok bandeng segar di Kota Bekasi, Jawa Barat. Pengambilan data dengan teknik purposive dan snowball sampling, dimulai dari IKM pengolah, pengecer dan pengepul di Kota Bekasi sampai ke pembudidaya bandeng di Desa Ciparage Jaya, Kecamatan Tempuran, Kabupaten Karawang. Kajian menggunakan analisis deskriptif, evaluasi dengan membandingkan aktivitas anggota rantai pasok dengan standar yang ada, analisis Strenghts, Weaknesses, Opportunities and Threaths (SWOT), serta Analytic Hierarchy Process (AHP). Hasil evaluasi menunjukkan terdapat gap antara aktivitas masing-masing anggota rantai pasok dengan Standar Nasional Indonesia (SNI) yaitu (1) penerapan GMP dan SSOP oleh IKM pengolah, (2) cara pengangkutan dan penyimpanan ikan segar oleh pengepul dan pengecer, (3) cara budidaya ikan yang baik oleh pembudidaya, dan (4) manajemen rantai pasok oleh seluruh anggota rantai pasok. Berdasarkan analisis matriks SWOT dan AHP, strategi pengembangan rantai pasok oleh aktor adalah: (1) pembentukan jaringan perolehan bahan baku dan jaringan pemasaran oleh IKM pengolah $(0,326)$; (2) peningkatan mutu SDM oleh pemerintah $(0,249)$; $(3)$ pembentukan kelembagaan oleh pembudidaya $(0,230)$, dan (4) menjalin kemitraan perolehan biaya usaha oleh pengepul $(0,195)$.
\end{abstract}

Kata kunci: bandeng, industri kecil menengah, pengembangan sistem, strategi manajemen rantai pasok

\begin{abstract}
Case study is conducted towards 12 SME milkfish processors in Bekasi, at which its raw materials are originated from Karawang Regency through a fresh milkfish supply chain. The potentcy of Karawang Regency as a milkfish producer does not guarantee continuous availability of the raw materials. The objectives of this study were: (1) To evaluate supply chain; and (2) To compile a priority strategy of fresh milkfish supply chain management in Bekasi, West Java. Data collection was conducted by purposive and snowball sampling techniques, starting from SME processors, retailers and collective traders in Bekasi, to milkfish farmers in Ciparage Jaya Village, Tempuran Sub-District, Karawang Regency. The study used descriptive analysis, evaluation by comparing the activities of the members of the supply chain with the existing standards, Strength, Weaknesses, Opportunities and Threats (SWOT) analysis and Analytic Hierarchy Process (AHP). The evaluation result showed there was gap between the activities of
\end{abstract}

\footnotetext{
*) Korespondensi:

KKP, Jl. Medan Merdeka Timur No. 16 Gedung Mina Bahari III, Lt. 14 Jakarta 10110; email: yefniwidria@gmail.com
} 
each supply chain member with the Indonesian National Standard (SNI) namely (1) implementation of GMP and SSOP by SME processors, (2) means of transport and storage of fresh fish by collective trader and retailer, (3) good aquaculture practices by farmer and (4) supply chain management by all members along the supply chain. Based on the SWOT and AHP matrix analyses, the development strategies of supply chain by actor was (1) the formation of raw material procurement network and marketing network by SME processor (0.326); (2) the quality improvement of human resource by the government (0.249); (3) the formation of organizations by farmer (0.230), and (4) maintaining partnership in business procurement cost by collective trader (0.195).

Key words: milkfish, micro scale processing unit, system development, supply chain management strategy

\section{PENDAHULUAN}

Sektor kelautan dan perikanan merupakan sektor potensial sumber pertumbuhan ekonomi, sumber penghidupan masyarakat banyak dan harapan masa depan bangsa. Produk Domestik Bruto (PDB) sub sektor perikanan memegang peranan strategik dalam memberikan kontribusi pada PDB Nasional. Capaian PDB sub sektor perikanan pada periode 2009-2012 mengalami peningkatan rataan 13,07\% (dari Rp177 trilyun menjadi Rp255 trilyun). PDB nasional pada periode yang sama meningkat $13,95 \%$ (dari Rp5.606 trilyun menjadi Rp8.242 trilyun). Pertumbuhan PDB sub sektor perikanan pada periode tersebut $6,49 \%$ sedikit lebih tinggi dibandingkan dengan PDB nasional (6,31\%).

Kontribusi ekonomi sektor perikanan ini akan dapat terus ditingkatkan, apabila pemerintah, khususnya Kementerian Kelautan dan Perikanan (KKP) dapat mengatasi sejumlah tantangan pengembangan sektor kelautan dan perikanan. Salah satu tantangan tersebut adalah rataan utilitas unit pengolah ikan pada tahun 2013 hanya 56,09\%. Angka tersebut mengindikasikan pasokan atau ketersediaan bahan baku unit pengolahan ikan masih minim, atau unit pengolahan tidak memperoleh bahan baku cukup untuk menjamin keberlangsungan proses pengolahan, baik dari sektor perikanan tangkap maupun perikanan budidaya.

Ikan Bandeng (Chanos-chanos) merupakan salah satu komoditas yang dapat diperoleh dari sektor perikanan budidaya. Utilitas kelompok pengolah bandeng dapat ditingkatkan melalui penyesuaian produk, mutu tinggi, pengurangan biaya dan kecepatan distribusi dengan manajemen rantai pasok terintegrasi Aktivitas pengadaan produk, pengubahan menjadi barang setengah jadi dan produk akhir, serta pengiriman ke konsumen akhir (Anwar, 2011).

Terdapat 12 Industri Kecil Menengah (IKM) yang melakukan usaha pengolahan bandeng bernilai tambah dengan skala mikro di Kota Bekasi. Berbagai produk olahan bandeng yang dihasilkan adalah bandeng presto, pindang bandeng dan otak-otak bandeng. Bahan baku utama berasal dari hasil lokal, yaitu Kabupaten Karawang melalui suatu rantai pasok bandeng segar. Namun, produksi bandeng Kab. Karawang ternyata belum menjamin ketersediaan bahan baku bagi kelompok pengolah bandeng di Kota Bekasi secara berkelanjutan.

Berdasarkan studi literatur terdapat beberapa kajian tentang rantai pasok, namun belum ditemukan penelitian tentang pengembangan sistem rantai pasok bandeng segar. Setiawan, et al (2011) pernah melakukan kajian tentang kinerja rantai pasok dengan judul "Studi Peningkatan Kinerja Manajemen Rantai Pasok Sayuran Dataran Tinggi di Jawa Barat". Kajian tersebut bertujuan mengembangkan kriteria dan alternatif pemilihan sayuran dataran tinggi yang berpotensi untuk ditingkatkan kinerja rantai pasoknya, mengidentifikasi struktur rantai pasok dan nilai tambah produk sayuran dataran tinggi yang dapat ditingkatkan kinerja rantai pasoknya, merancang dan mengimplementasikan model pengukuran kinerja rantai pasok sayuran terpilih, serta merumuskan strategi peningkatan rantai pasok sayuran terpilih. Nugraha (2011) melakukan kajian mengenai rumusan strategi rantai pasok menggunakan alat analisis AHP dan SWOT dengan judul "Analisis Rumusan Strategi Rantai Pasokan Minyak akar Wangi di Kabupaten Garut, Jawa Barat". Kajian bertujuan menganalisis rantai pasok minyak akar wangi, menganalisis faktor internal dan eksternal rantai pasok minyak akar wangi dan merumuskan strategi rantai pasok minyak akar wangi.

Penelitian ini bertujuan mengidentifikasi rantai pasok bandeng segar, mengidentifikasi dan menganalisis faktor internal dan eksternal yang memengaruhi rantai pasok bandeng segar, serta mengusulkan alternatif rekomendasi strategi rantai pasok bandeng segar untuk meningkatkan 
daya saing produk olahan berbahan baku bandeng segar di Kota Bekasi, Jawa Barat.

\section{METODE PENELITIAN}

Pengambilan contoh dilakukan dengan metoda purposif dan snowball sampling. Pengumpulan data primer dengan mengajukan kuesioner, wawancara dan observasi langsung. Data sekunder diperoleh melalui studi literatur (desk study) yaitu dari Dinas Kelautan dan Perikanan, Badan Pusat Statistik (BPS) dan laporan penelitian terdahulu. Kajian bersifat deskriptif, menggambarkan aktivitas anggota rantai pasok dengan SNI sebagai faktor pembanding serta mengarahkan kajian kepada pemecahan permasalahan rantai pasok.

Target populasi adalah seluruh anggota rantai pasok bandeng segar, yaitu pengolah bandeng, pengecer, pengepul dan pembudidaya bandeng. Diagram tulang ikan digunakan untuk mengidentifikasi unsur rantai pasok, analisis SWOT digunakan untuk memetakan dan menganalisis faktor-faktor eksternal dan internal yang memengaruhi efektifitas rantai pasok. AHP digunakan untuk menentukan rekomendasi alternatif strategi dalam meningkatkan efektifitas rantai pasok bandeng segar di Kota Bekasi.

\section{HASIL DAN PEMBAHASAN}

\section{Potensi Bandeng Kabupaten Karawang}

Provinsi Jawa Barat menempati peringkat ke tiga di Indonesia sebagai penghasil bandeng setelah Provinsi Jawa Timur dan Sulawesi Selatan. Karawang merupakan salah satu kabupaten di
Jawa Barat memiliki potensi produksi budidaya ikan bandeng yang potensial untuk memenuhi kebutuhan bahan baku unit pengolahan ikan bandeng di Propinsi Jawa Barat termasuk di Kota Bekasi dan sekitarnya. Berdasarkan sumber daya alam (SDA) yang tersedia, rantai pasok bandeng segar di Kota Bekasi yang memiliki 12 IKM pengolah bandeng seharusnya tidak mengalami kendala bahan baku.

\section{Identifikasi Rantai Pasok Bandeng Segar}

Rantai pasok terdiri dari rangkaian kegiatan produktif yang terhubung antara aktifitas nilai yang satu dengan dengan lain yang membentuk rantai nilai industri (Nugraha, 2011). Anggota rantai pasok bandeng segar di Kota Bekasi terdiri 12 IKM pengolah, 1 pengecer, 1 pengepul, dan. 5 pembudidaya bandeng. Terdapat tiga kegiatan yang harus dikelola dalam rantai pasok ikan bandeng segar Kota Bekasi, yaitu: (1) aliran fisik dari hulu ke hilir, merupakan pendistribusian bahan baku yang diperoleh dari pembudidaya bandeng dan didistribusikan oleh pengepul ke pengecer dan pasar yang kemudian diolah menjadi produk bernilai tambah berupa bandeng presto oleh para IKM pengolah. Selanjutnya bandeng presto didistribusikan oleh para IKM pengolah sehingga sampai ke konsumen; (2) aliran pembayaran berupa uang dan kredit yang mengalir dari hilir ke hulu dan (3) aliran informasi berupa jumlah bahan baku yang dibutuhkan, harga dan jadwal penen yang bisa terjadi dari hulu ke hilir atau sebaliknya. Rantai pasok bandeng segar di Kota Bekasi disajikan pada Gambar 1.

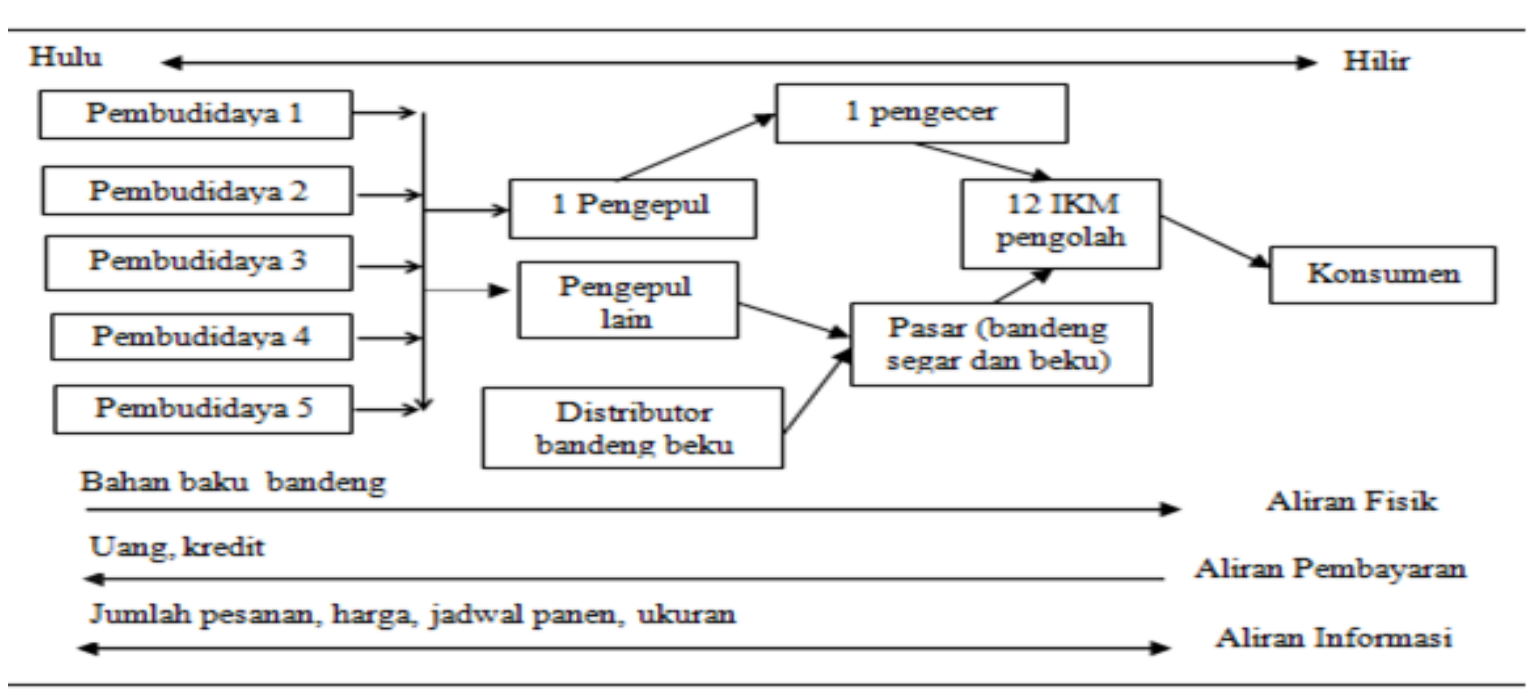

Gambar 1. Anggota rantai pasok bandeng segar di Kota Bekasi 
Gambar 1 menjelaskan aliran pemenuhan kebutuhan bahan baku melalui IKM pengecer untuk 12 IKM pengolah di Kota Bekasi dari pembudidaya di Kabupaten Karawang melalui suatu rantai pasok bandeng segar. Pengepul di Kota Bekasi memperoleh bahan baku dari 5 pembudidaya dan mendistribusikan kepada 1 IKM pengecer. Jika pengepul tidak memperoleh atau tidak dapat menyediakan bahan baku dengan berat atau ukuran serta sesuai jumlah kebutuhan, IKM pengolah dapat memperoleh bahan baku dari pasar. Bandeng segar di pasar dipasok oleh pengepul lain dengan kemungkinan pengepul lain tersebut juga memperoleh bandeng segar dari pembudidaya yang sama dengan pengepul rantai pasok. Harga bandeng segar di pasar lebih mahal dibanding harga yang ditawarkan oleh pengecer.

Alternatif terakhir pemenuhan kebutuhannya bahan baku adalah menggunakan bandeng beku yang biasa disebut dengan ikan PT atau ikan dus. IKM pengolah kurang menyukai kualitas ikan PT karena rasa bandeng presto yang dihasilkan sering tidak sesuai dengan harapan yaitu berbau lumpur sehingga mengecewakan pelanggan. Bandeng beku ini berasal dari berbagai daerah di Indoneasia terutama dari Kota Surabaya.

\section{IKM Pengolah dan Pengecer}

Pengamatan dilakukan terhadap 12 IKM pengolah dengan produk olahan yang dihasilkan yaitu bandeng presto. Tenaga kerja yang melakukan kegiatan pengolahan adalah anggota keluarga masing-masing IKM. Seluruh anggota keluarga ikut serta dalam proses pengolahan bandeng mulai dari penerimaan bahan baku sampai pemasaran. Kepala keluarga merupakan petugas khusus di bidang pemasaran, yaitu memasarkan bandeng presto dengan berkeliling dari pagi hingga siang hari menggunakan sepeda motor yang dilengkapi boks kayu bertuliskan Bandeng Presto Duri Lunak. Setiap IKM pengolah memiliki wilayah pemasaran tertentu yang telah disepakati 12 IKM.

Setiap IKM pengolah melakukan proses pengolahan dengan jumlah bervariasi. Kebutuhan bahan baku dalam setiap produksi yang dilakukan oleh IKM pengolah 23,33 $\mathrm{kg}$ dengan jumlah produksi antara 16-17 kali dalam sebulan. Jika jumlah rataan produksi 16,5 kali/bulan, maka bahan baku yang dibutuhkan dalam proses produksi $4.620 \mathrm{~kg} / \mathrm{bulan}$. Tabel 1 menjelaskan rataan jumlah bahan baku yang digunakan pada setiap kali proses produksi.

Tabel 1. Rataan jumlah bahan baku pada setiap kali proses produksi

\begin{tabular}{cc}
\hline IKM Pengolah & Jumlah $(\mathrm{kg})$ \\
\hline A, B,C & 15 \\
D, E, F, G & 20 \\
H, I, J & 25 \\
K & 30 \\
L & 50 \\
\hline
\end{tabular}

Pengolahan bandeng segar perlu memperhatikan persyaratan dan tata cara produksi yang baik atau Good Manufacturing Process (GMP) dan persyaratan sanitasi unit pengolahan ikan atau Sanitation Standard Operating Procedure (SSOP). Tabel 2 menunjukkan gap analysis yang membandingkan GMP dan SSOP yang telah dipraktikan oleh IKM pengolah dengan GMP dan SSOP yang telah ditetapkan dalam SNI 4106.3:2009.

Berdasarkan gap analysis, diketahui bahwa terdapat kesenjangan GMP dan SSOP yang telah ditetapkan dalam SNI dengan GMP dan SSOP yang dipraktikkan oleh IKM pengolah. Sebagian besar kesenjangan terjadi pada prosedur pencegahan kontaminasi, sanitasi peralatan serta lay out ruangan yang digunakan saat proses pengolahan. IKM pengolah diharapkan dapat menyesuaikan penanganan dan GMP, serta SSOP dengan standar yang telah ditetapkan dalam SNI.

\section{Pengepul Bandeng}

Pengepul melakukan pembelian bandeng segar di dua tempat, yaitu:

1. Tambak

Pengepul langsung membeli bandeng ke tambak di Kecamatan Tanjung Pakis. Pembelian langsung biasa dilakukan oleh pengepul ketika memiliki kendala dalam mendapatkan modal cukup. Pengepul yang langsung membeli bandeng ke tambak harus melakukan penawaran dengan pembudidaya terlebih dahulu dan meminta kesepakatan penangguhan jatuh tempo pembayaran atau pembayaran dengan perjanjian. Pembudidaya akan lebih memilih menjual bandengnya kepada pengepul yang sudah dikenal dan mejalin jaringan kerjasama dengan pembudidaya. 
Tabel 2. Gap analysis GMP dan SSOP

\begin{tabular}{|c|c|c|c|}
\hline No & GMP, SSOP & SNI & IKM Pengolah \\
\hline 1 & $\begin{array}{l}\text { Penyimpanan } \\
\text { bahan baku }\end{array}$ & $\begin{array}{l}\text { Penyimpanan bahan baku } \\
\text { Bahan baku disimpan dalam wadah yang baik } \\
\text { dan diberi es atau dengan metode pendinginan } \\
\text { yang sesuai, sehingga mencapai suhu produk } 0 \\
{ }^{\circ} \mathrm{C}-5^{\circ} \mathrm{C} \text {. }\end{array}$ & $\begin{array}{l}\text { Bahan baku disimpan dalam styroform } \\
\text { yang diberi es, agar tidak terjadi } \\
\text { penurunan mutu bahan baku }\end{array}$ \\
\hline 2 & $\begin{array}{l}\text { Bahan } \\
\text { penolong }\end{array}$ & $\begin{array}{l}\text { Bahan penolong } \\
\text { Air: memenuhi persyaratan mutu air minum, } \\
\text { Es: ditangani dan disimpan di tempat yang } \\
\text { bersih agar terhindar dari kontaminasi. }\end{array}$ & $\begin{array}{l}\text { Menggunakan air sumur, tetapi belum } \\
\text { diuji apakah memenuhi persyaratan } \\
\text { mutu air minum. } \\
\text { Es : dibuat sendiri dari air sumur }\end{array}$ \\
\hline 3 & $\begin{array}{l}\text { Bahan } \\
\text { tambahan }\end{array}$ & $\begin{array}{l}\text { Bahan tambahan } \\
\text { Tidak merugikan, membahayakan kesehatan } \\
\text { dan memenuhi standar mutu }\end{array}$ & $\begin{array}{l}\text { Menggunakan bahan tambahan berupa } \\
\text { garam dan bumbu yang dibuat sendiri }\end{array}$ \\
\hline 4 & Peralatan & $\begin{array}{l}\text { Persyaratan peralatan } \\
\text { Peralatan pengolahan harus rata, tidak } \\
\text { mengelupas, tidak berkarat, tidak merupakan } \\
\text { sumber cemaran jasad renik, tidak retak, tidak } \\
\text { menyerap air dan mudah dibersihkan. }\end{array}$ & $\begin{array}{l}\text { Pengolah masih menggunakan talenan } \\
\text { berbahan kayu yang dapat menjadi } \\
\text { sumber kontaminasi. }\end{array}$ \\
\hline 5 & $\begin{array}{l}\text { Perancangan } \\
\text { atau tata letak }\end{array}$ & $\begin{array}{l}\text { Perancangan atau tata letak harus dapat } \\
\text { mencegah kontaminasi silang, dijamin juga } \\
\text { adanya pemisahan dan perlindungan produk } \\
\text { selama penyimpanan, pembersihan dan sanitasi } \\
\text { daerah penanganan atau pengolahan pangan, } \\
\text { serta peralatan ditangani dengan baik }\end{array}$ & $\begin{array}{l}\text { Pengolahan dilakukan di dapur rumah } \\
\text { tangga dan tidak ada layout dan alur } \\
\text { proses, sehingga memungkinkan terjadi- } \\
\text { nya kontaminasi silang; Ruang proses } \\
\text { berdekatan dengan toilet; Tidak dileng- } \\
\text { kapi fasilitas sanitasi }\end{array}$ \\
\hline
\end{tabular}

2. Tempat Pelelangan Hasil Perikanan (TPHP) Pengepul dapat memperoleh bahan baku yang dibutuhkan, jika memiliki modal cukup untuk melakukan transaksi lelang. Sistem lelang bandeng dimulai dari pembelian bandeng dalam jumlah kecil/ Sistem ini diterapkan untuk melindungi IKM yang hanya membutuhkan bahan baku dalam jumlah kecil dari pengusaha bandeng skala besar yang memiliki modal dan dapat melakukan pembelian langsung dalam jumlah besar.

Sistem pembayaran tergantung pada jumlah panen, dimana jika hasil panen banyak pengepul membawa hasil panen terlebih dahulu dan membayar pada saat pembelian bandeng selanjutnya. Bagi para pengepul yang memiliki modal cukup, biasanya melakukan pembayaran secara tunai dengan harga lebih murah. Jika hasil panen sedikit, para pembudidaya dan tengkulak biasanya menghendaki sistem pembayaran secara tunai dan hanya melayani penjualan dengan jumlah banyak dan tidak melayani penjualan dalam jumlah sedikit.

Pengepul mendistribusikan bandeng segar ke dua IKM penyalur bandeng yang berlokasi di Kecamatan Rawa Lumbu, Bekasi Timur dan Kecamatan Bantar Gebang, Kota Bekasi. Gambar
2 menjelaskan jumlah penjualan pengepul kepada IKM penyalur bandeng di Kota Bekasi. Berdasarkan gambar tersebut diketahui bahwa jumlah penjualan sangat fluktuatif. Pengepul menyediakan bahan baku dengan jumlah hampir medekati jumlah yang dibutuhkan IKM pengolah hanya pada bulan Desember tahun 2014 dan bulan Januari tahun 2015, dan hampir tidak memperoleh bahan baku sama sekali pada bulan Mei dan Juni tahun 2014.

Pengepul membawa bandeng segar dari Kabupaten Karawang ke Kota Bekasi dengan sarana angkut dan peralatan sederhana. Pengepul perlu memperhatikan proses pendistribusian ikan segar dengan standar sesuai SNI 2729: 2013 tentang Ikan Segar, agar mutu bandeng tetap terjaga sampai ke IKM pengecer. Tabel 3 menjabarkan perbandingan antara proses distribusi yang telah ditetapkan dalam SNI dengan proses distribusi yang dilaksanakan oleh pengepul. Berdasarkan Tabel 3 diketahui bahwa proses distribusi ikan segar yang dilakukan oleh pengepul belum sesuai standar yang telah ditetapkan dalam SNI, karena keranjang yang dilapisi plastik tidak bisa mempertahankan suhu dingin yang dibutuhkan ikan segar serta plastik tidak dapat menjaga agar es tidak meleleh sehingga berceceran di sepanjang jalan menuju IKM pengolah. 


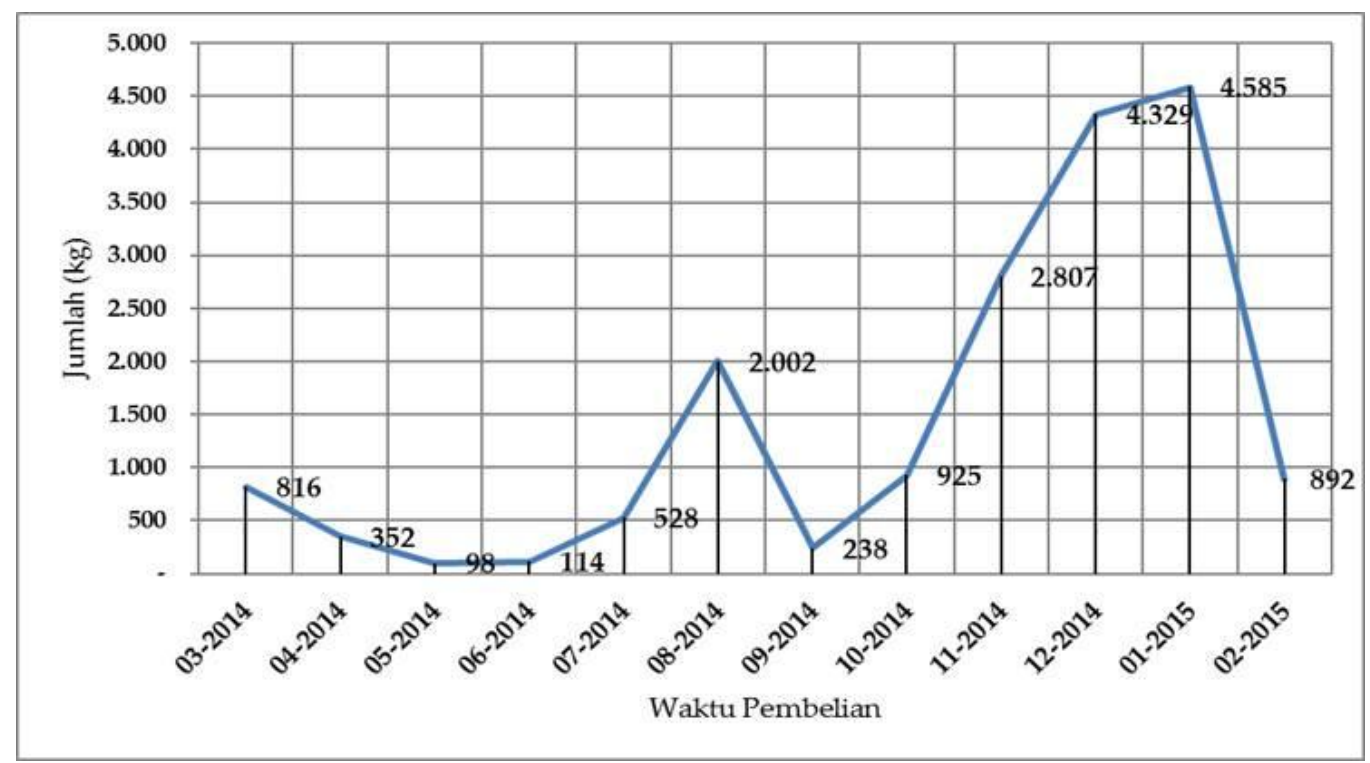

Gambar 2. Jumlah penjualan bandeng segar pengepul

Tabel 3. Gap analysis pengepul bandeng

\section{SNI pengangkutan ikan Segar}

Kendaraan yang digunakan untuk pengangkutan ikan harus mampu mempertahankan suhu dingin yang dibutuhkan ikan segar

\section{Pengangkutan ikan segar oleh pengepul}

Pendistribusian dan pemasaran menggunakan dua keranjang bambu yang dilapisi plastik hitam, serta diberi es. Keranjang bambu diletakkan pada sisi kanan dan kiri motor

\section{Pembudidaya dan Pemilik Modal}

Pembudidaya bandeng dan pemilik modal sebagai mata rantai di bagian hulu. Pembudidaya bandeng melakukan kegiatan budidaya bandeng, mulai dari persiapan tambak dan benih, pemberian pakan dan pupuk sampai tahap pemanenan. Pembudidaya bandeng ada yang membiayai sendiri seluruh biaya produksi dan ada juga yang menjalin mitra kerja dengan pemilik modal atau menerima investasi dari pihak luar. Jika pembudidaya membiayai seluruh biaya produksi, maka pembudidaya dapat menentukan sendiri harga jual dan memilih calon pembeli atau menjalin mitra penjualan.

Pemilik modal tambak rantai pasok adalah orang yang menginvestasikan modalnya di budidaya tambak bandeng. Pemilik modal menyediakan biaya operasional produksi bandeng mulai dari bibit, pakan, pupuk, listrik untuk penerangan tambak dan biaya lainnya. Pemilik modal biasanya membuat perjanjian tertentu dengan pemilik tambak, persentase biaya yang ditanggung pemilik modal tergantung kesepakatan pemilik tambak dan pemilik modal. Jika pemilik modal membiayai seluruh biaya produksi, biasanya kentungan penjualan $70 \%$ untuk pemilik tambak dan $30 \%$ untuk pemilik modal. Pemilik modal juga dapat membeli langsung panen bandeng atau membeli dengan sistem ijon saat bandeng masih di tambak dan belum dipanen. Pembudidaya adalah sumber bahan baku bagi pengepul. Sistem pembayaran tergantung pada jumlah panen, jika hasil panen banyak pengepul dapat membawa hasil panen terlebih dahulu dan membayar pada saat pembelian bandeng selanjutnya. Bagi para pengepul yang memiliki modal cukup biasanya melakukan pembayaran secara tunai dengan harga yang lebih murah. Jika hasil panen sedikit pembudidaya biasanya menghendaki sistem pembayaran secara tunai dan tidak melayani penjualan dalam jumlah sedikit. Dengan demikian hanya pengepul yang membawa uang tunai dan membeli dalam jumlah besar yang akan memperoleh bahan baku. Dengan pembayaran tunai dan penjualan langsung di area tambak, proses penjualan akan cepat selesai dan keuntungan cepat diperoleh.

Pembudidaya bandeng perlu menyesuaikan proses budidayanya dengan standar yang telah ditetapkan dalam Keputusan Menteri Kelautan dan Perikanan No. KEP.02/Men/2007 tentang Cara Budidaya Ikan yang Baik (CBIB). Tabel 4 menguraikan proses budidaya menurut CBIB dan proses budidaya yang telah diterapkan 
oleh pembudidaya bandeng. Berdasarkan Tabel 4, dapat diketahui bahwa proses budidaya yang dilakukan oleh pembudidaya bandeng belum sesuai standar CBIB.

Tabel 4. Gap analysis pembudidaya

\begin{tabular}{ll}
\hline \multicolumn{1}{c}{ Standar CBIB } & \multicolumn{1}{c}{ Pembudidaya bandeng } \\
\hline Pakan bersertifikat & $\begin{array}{l}\text { Tidak memperhatikan } \\
\text { sertifikasi pakan }\end{array}$ \\
\hline $\begin{array}{l}\text { Benih memiliki Surat } \\
\text { Keterangan Asal (SKA) }\end{array}$ & $\begin{array}{l}\text { Tidak menggunakan SKA, } \\
\text { pembudidaya hanya } \\
\text { menggunakan standar } \\
\text { keseragaman benih yang } \\
\text { digunakan }\end{array}$ \\
& $\begin{array}{l}\text { Tidak memiliki SOP, proses } \\
\text { budidaya didasarkan } \\
\text { kebiasaan yang telah } \\
\text { dilakukan turun temurun } \\
\text { Operating Procedures } \\
\text { (SOP) mulai dari } \\
\text { pengolahan kolam, } \\
\text { pengadaan benih } \\
\text { sampai panen }\end{array}$ \\
\hline
\end{tabular}

\section{Analisis Manajemen Rantai Pasok}

Manajemen rantai pasok dibutuhkan untuk menghadapi segala ancaman dan kelemahan anggota rantai pasok. Tabel 5 menyajikan gap analysis yang membandingkan antara sistem manajemen rantai pasok berdasarkan SNI ISO 28000:2009 tentang spesifikasi sistem keamanan pada manajemen rantai pasok dengan sistem manajemen rantai pasok yang dilakukan oleh rantai pasok bandeng segar di Kota Bekasi. Berdasarkan gap analysis, diketahui sistem manajemen rantai pasok bandeng segar di Kota Bekasi belum menerapkan sistem manajemen menurut standar yang telah ditetapkan dalam SNI ISO 28000:2009. Hal ini disebabkan tidak terdapat manajemen puncak yang bertugas melakukan fungsi manajemen, sumberdaya manusia kurang terdidik (lack of knowledge), kedisiplinan rendah, kultur keamanan pangan (food safety culture) belum terbentuk dan terbatasnya sarana usaha.

Tabel 5. Gap analysis manajemen rantai pasok

\begin{tabular}{|c|c|c|}
\hline No & SNI rantai pasok & Rantai pasok bandeng segar di Kota Bekasi \\
\hline 1 & $\begin{array}{l}\text { Memiliki manajemen puncak yang mengkoordinir } \\
\text { seluruh kegiatan anggota rantai pasok }\end{array}$ & $\begin{array}{l}\text { Tidak memiliki manajemen puncak, anggota rantai } \\
\text { pasok melakukan kegiatan tidak terintegrasi satu } \\
\text { sama lain }\end{array}$ \\
\hline 2 & $\begin{array}{l}\text { Memiliki kerangka kerja yang memungkinkan } \\
\text { disusunnya sasaran, target dan manajemen strategi } \\
\text { spesifik }\end{array}$ & Tidak memiliki kerangka kerja \\
\hline 3 & $\begin{array}{l}\text { Memiliki prosedur penilaian ancaman dan dan } \\
\text { tindakan pengendalian ancaman, baik internal } \\
\text { maupun eksternal }\end{array}$ & $\begin{array}{l}\text { Tidak bisa menilai ancaman dan menghindari } \\
\text { ancaman yang ada }\end{array}$ \\
\hline 4 & $\begin{array}{l}\text { Seluruh kegiatan didokumentasikan, } \\
\text { diimplementasikan dan dipelihara }\end{array}$ & Tidak memiliki catatan administrasi \\
\hline 5 & $\begin{array}{l}\text { Melakukan manajemen informasi, data dan } \\
\text { komunikasi }\end{array}$ & $\begin{array}{l}\text { Cenderung tidak mengetahui data dan informasi } \\
\text { penting untuk perkembangan rantai pasok }\end{array}$ \\
\hline 6 & $\begin{array}{l}\text { Memelihara stuktur organisasi dari tanggung jawab } \\
\text { dan wewenang }\end{array}$ & Tidak memiliki stuktur organisasi \\
\hline 7 & $\begin{array}{l}\text { Tanggungjawab dan wewenang ditetapkan, } \\
\text { dikomunikasikan dan didokumentasikan kepada } \\
\text { individu yang bertanggungjawab }\end{array}$ & $\begin{array}{l}\text { Tidak terdapat pembagian tugas yang jelas dan tidak } \\
\text { ada sistem dokumentasi }\end{array}$ \\
\hline 8 & $\begin{array}{l}\text { Personel yang betanggungjawab dikualifikasi dari } \\
\text { segi pendidikan, pelatihan dan/atau pengalaman. } \\
\text { Rekam kompetensi dan pelatihan } \\
\text { didokumentasikan }\end{array}$ & $\begin{array}{l}\text { Personel tidak dikualifikasi dari segi pendidikan, } \\
\text { pelatihan dan/atau pengalaman. Rekam kompetensi } \\
\text { dan pelatihan tidak didokumentasikan }\end{array}$ \\
\hline 9 & $\begin{array}{l}\text { Memiliki prosedur yang memastikan bahwa } \\
\text { informasi manajemen dikomunikasikan pada } \\
\text { pegawai terkait }\end{array}$ & $\begin{array}{l}\text { Tidak memiliki prosedur yang memastikan bahwa } \\
\text { informasi manajemen dikomunikasikan pada } \\
\text { pegawai terkait }\end{array}$ \\
\hline 10 & $\begin{array}{l}\text { Memelihara sistem dokumentasi manajemen } \\
\text { keamanan }\end{array}$ & $\begin{array}{l}\text { Tidak memelihara sistem dokumenasi manajemen } \\
\text { keamanan }\end{array}$ \\
\hline 11 & $\begin{array}{l}\text { Menetapkan dan memelihara prosedur untuk } \\
\text { mengendalikan seluruh dokumen, data dan } \\
\text { informasi }\end{array}$ & $\begin{array}{l}\text { Tidak menetapkan dan memelihara prosedur untuk } \\
\text { mengendalikan seluruh dokumen data dan informasi }\end{array}$ \\
\hline
\end{tabular}




\section{Matriks EFE dan IFE}

Berdasarkan hasil analisis matriks EFE, peluang dan ancaman sistem manajemen rantai pasok bandeng Kota Bekasi memiliki skor 2,52 yang berarti bahwa rantai pasok masih berada di atas nilai rataan $(2,50)$. Total skor 2,52 mengindikasikan bahwa rantai pasok dapat merespon peluang dan ancaman yang ada. Nilai skor tersebut juga menunjukkan bahwa strategi manajemen rantai pasok dinilai masih dapat mengambil keuntungan dari peluang yang ada dan meminimalkan efek yang muncul dari ancaman eksternal.
Berdasarkan analisis matriks IFE untuk kekuatan dan kelemahan, faktor manajemen rantai pasok bandeng di Kota Bekasi memperoleh skor di atas rataan $(2,5)$ yaitu 2,85. Skor tersebut menunjukkan bahwa faktor-faktor internal rantai pasok bandeng segar di Kota Bekasi dapat memanfaatkan kekuatan serta meminimalisir kelemahan yang dimilikinya.

Hasil External Factor Evaluation (EFE) dan Internal Factor Evaluation (IFE) manajemen rantai pasok bandeng segar di Kota Bekasi dijelaskan pada Tabel 6 dan 7 .

Tabel 6. Hasil matriks EFE

\begin{tabular}{|c|c|c|c|c|c|}
\hline \multicolumn{2}{|c|}{ Peluang } & \multirow{2}{*}{$\frac{\text { Bobot (a) }}{4,8}$} & \multirow{2}{*}{$\begin{array}{c}\text { Relatif }(\mathrm{b}) \\
0,140\end{array}$} & \multirow{2}{*}{$\frac{\text { Rating (c) }}{3,8}$} & \multirow{2}{*}{$\frac{\text { Skor }(\mathrm{bxc})}{0,53}$} \\
\hline 1 & $\begin{array}{l}\text { Potensi sumberdaya alam Kab. Karawang } \\
\text { sebagai produsen bandeng }\end{array}$ & & & & \\
\hline 2 & Bandeng digemari relatif mudah & 4,8 & 0,140 & 3,4 & 0,48 \\
\hline 3 & Adanya dukungan pemerintah & 4,6 & 0,135 & 3,4 & 0,46 \\
\hline 4 & $\begin{array}{l}\text { Tingginya minat investasi pelaku usaha } \\
\text { budidaya bandeng }\end{array}$ & 4,4 & 0,129 & 3,4 & 0,44 \\
\hline & Total & 18,6 & 0,544 & & 1,91 \\
\hline \multicolumn{6}{|c|}{ Ancaman } \\
\hline 1 & $\begin{array}{l}\text { Cuaca atau curah hujan tinggi Kab. } \\
\text { Karawang mempengaruhi musim tanam } \\
\text { bandeng }\end{array}$ & 4,0 & 0,117 & 1,6 & 0,19 \\
\hline 2 & Budidaya bandeng bersifat musiman & 4,0 & 0,117 & 1,0 & 0,12 \\
\hline 3 & Fluktuasi harga bahan baku & 3,8 & 0,111 & 1,4 & 0,16 \\
\hline 4 & $\begin{array}{l}\text { Persaingan perolehan bahan baku dengan } \\
\text { industri besar }\end{array}$ & 3,8 & 0,111 & 1,4 & 0,16 \\
\hline & Total & 15,6 & 0,456 & & 0,62 \\
\hline & tal bobot $\mathrm{x}$ skor untuk Faktor Internal & 34,2 & 1,000 & & 2,52 \\
\hline
\end{tabular}

Tabel 7. Hasil matriks IFE

\begin{tabular}{|c|c|c|c|c|c|}
\hline \multicolumn{2}{|c|}{ Kekuatan } & \multirow{2}{*}{$\frac{\text { Bobot }(\mathrm{a})}{4,0}$} & \multirow{2}{*}{$\frac{\text { Relatif }(b)}{0,138}$} & \multirow{2}{*}{$\frac{\text { Rating }(\mathrm{c})}{3,4}$} & \multirow{2}{*}{$\frac{\text { Skor }(\mathrm{bxc})}{0,47}$} \\
\hline 1 & Anggota rantai pasok pemilik usaha & & & & \\
\hline 2 & Pembayaran fleksibel & 4,8 & 0,166 & 3,8 & 0,63 \\
\hline 3 & Kepercayaan jangka panjang & 3,8 & 0,131 & 3,2 & 0,42 \\
\hline 4 & Komunikasi informal dan cepat & 5,2 & 0,179 & 3,8 & 0,68 \\
\hline & Total & 17,8 & 0,614 & & 2,20 \\
\hline \multicolumn{6}{|c|}{ Kelemahan } \\
\hline 1 & $\begin{array}{l}\text { Tidak memiliki sarana sistem rantai dingin, } \\
\text { tidak menerapkan GMP dan SSOP }\end{array}$ & 3,0 & 0,103 & 1,8 & 0,19 \\
\hline 2 & Kurang modal dan akses pembiayaan & 2,6 & 0,090 & 1,8 & 0,16 \\
\hline 3 & Mutu SDM rendah & 3,2 & 0,110 & 2,0 & 0,22 \\
\hline 4 & $\begin{array}{l}\text { Teknologi budidaya dan pengolahan masih } \\
\text { konvensional, terdapat gap analysis }\end{array}$ & 2,4 & 0,083 & 1,0 & 0,08 \\
\hline & Total & 11,2 & 0,386 & & 0,65 \\
\hline & tal bobot $x$ skor untuk Faktor Internal & 29,0 & 0,772 & & 2,85 \\
\hline
\end{tabular}




\section{Analisis SWOT}

Berdasarkan hasil analisis matriks SWOT, diperoleh beberapa alternatif strategi yang dapat diaplikasikan untuk mengembangkan sistem manajemen rantai pasok bandeng segar di Kota Bekasi (Gambar 3).

\section{Penetapan Prioritas Unsur Kriteria, Aktor dan Alternatif Strategi}

Penetapan prioritas unsur kriteria, aktor dan alternatif strategi dilakukan dengan menggunakan AHP. Langkah-langkah yang dilakukan dalam AHP menggunakan software Expert Choice adalah mengidentifikasi masingmasing unsur dalam hirarki AHP berdasarkan pendapat lima orang pakar untuk menguraikan masalah strategi pengembangan sistem manajemen rantai pasok menjadi suatu hirarki dalam satu struktur multilevel. Level pertama adalah penetapan tujuan, yaitu pengembangan sistem manajemen rantai pasok bandeng segar yang diikuti dengan penetapan kriteria-kriteria yang cocok untuk dipertimbangkan sebagai kriteria yang memengaruhi efektifitas rantai pasok. Kriteria tersebut adalah SDA, logistik/sarpras, harga dan modal. Tahap selanjutnya penentuan aktor yang terlibat atau merupakan anggota rantai pasok dan instansi yang berpengaruh terhadap rantai pasok.

Pada hirarki ini aktor yang dipilih adalah pembudidaya, pengepul, pemerintah dan IKM pengolah. Langkah terakhir adalah menentukan prioritas strategi alternatif yang akan dilaksanakan oleh setiap aktor untuk memecahkan masalah yang dihadapi rantai pasok. Delapan strategi yang dihasilkan pada matriks SWOT, dirangkum atau diringkas menjadi empat strategi pada AHP yaitu peningkatan mutu SDM, pembentukan jaringan bahan baku dan jaringan pemasaran, pembentukan kelembagaan serta menjalin kemitraan perolehan biaya usaha. Rangkuman strategi matriks SWOT menjadi strategi pada AHP disajikan pada Tabel 8. Strategi yang dipilih adalah peningkatan mutu SDM, pembentukan jaringan bahan baku dan jaringan pemasaran, pembentukan kelembagaan dan pemberian modal. Struktur hirarki untuk strategi pengembangan sistem manajemen rantai pasok tertera pada Gambar 4.

\begin{tabular}{|c|c|c|}
\hline Faktor Eksternal & $\begin{array}{l}\quad \text { Kekuatan (S) } \\
\text { S1. Anggota rantai pasok adalah } \\
\text { pemilik usaha } \\
\text { S2. Pembayaran fleksibel } \\
\text { S3. Kepercayaan jangka panjang } \\
\text { S4. Komunikasi informal dan } \\
\text { cepat }\end{array}$ & $\begin{array}{l}\text { Kelemahan }(W) \\
\text { W1. Tidak memiliki sarana sistem } \\
\text { rantai dingin, tidak menerapkan } \\
\text { GMP dan SSOP } \\
\text { W2. Kurang modal dan akses } \\
\text { pembiayaan } \\
\text { W3. Mutu SDM rendah } \\
\text { W4.,Teknologi budidaya dan } \\
\text { pengolahan masih konvensional, } \\
\text { terdapat gap analysis }\end{array}$ \\
\hline $\begin{array}{l}\text { Peluang }(\mathrm{O}) \\
\text { O1. Potensi SDA Kab. Karawang } \\
\text { sebagai produsen bandeng } \\
\text { O2. Budidaya bandeng relatif mudah } \\
\text { O3. Adanya dukungan pemerintah } \\
\text { O4. Tingginya minat investasi pelaku } \\
\text { usaha budidaya bandeng }\end{array}$ & \begin{tabular}{l}
\multicolumn{1}{c}{ Strategi SO } \\
1. Peningkatan ketersediaan \\
ikan dipusat produksi (S2, S3, \\
O1, O2, O3, O4) \\
2. Peningkatan koordinasi dan \\
komunikasi dengan seluruh \\
anggota rantai pasok (S3, \\
S4,O3, O4)
\end{tabular} & \begin{tabular}{ll}
\multicolumn{1}{c}{ Strategi WO } \\
1. & $\begin{array}{l}\text { Pendidikan dan pelatihan SDM } \\
(\mathrm{W} 1, \mathrm{~W} 2, \mathrm{~W} 3, \mathrm{~W} 4, \mathrm{O} 1, \mathrm{O} 2, \mathrm{O}, \mathrm{O} 4)\end{array}$ \\
2. & $\begin{array}{l}\text { Menjalin kemitraan perolehan } \\
\text { biaya usaha }(\mathrm{W} 1, \mathrm{~W} 2, \mathrm{O} 3, \mathrm{O} 4)\end{array}$
\end{tabular} \\
\hline $\begin{array}{l}\text { Ancaman }(\mathrm{T}) \\
\text { T1. Cuaca atau curah hujan tinggi } \\
\text { Kab. Karawang mempengaruhi } \\
\text { musim tanam bandeng } \\
\text { T2. Budidaya bandeng bersifat } \\
\text { musiman } \\
\text { T3. Fluktuasi harga bandeng segar } \\
\text { T4. Persaingan perolehan bahan baku } \\
\text { dengan industri besar }\end{array}$ & \begin{tabular}{ll}
\multicolumn{1}{c}{ Strategi ST } \\
1. & Pembentukan organisasi \\
anggota rantai pasok \\
(S1,S4,T1,T3) \\
2. Penambahan suplier bahan \\
bahan baku dan promosi \\
produk (S3, S4, T2,T4)
\end{tabular} & $\begin{array}{l}\quad \text { Strategi WT } \\
\text { 1. Penggunaan teknologi produksi } \\
\text { lebih efisien dan efektif oleh IKM } \\
\text { Pengolah dan pembudidaya } \\
\text { bandeng (W4, T2, T3, T4) } \\
\text { 2. Perbaikan mutu dan inovasi } \\
\text { produk olahan perikanan } \\
\text { (W1,W4, T4) }\end{array}$ \\
\hline
\end{tabular}

Gambar 3. Matriks SWOT rantai pasok bandeng segar di Kota Bekasi 
Tabel 8. Ringkasan strategi matriks SWOT menjadi strategi alternatif AHP

\begin{tabular}{|c|c|c|}
\hline No & Strategi matriks SWOT & Strategi AHP \\
\hline 1 & Pendidikan dan pelatihan SDM (3) & \\
\hline 2 & $\begin{array}{l}\text { Penggunaan teknologi produksi yang lebih efisien dan efektif oleh } \\
\text { IKM Pengolah dan pembudidaya bandeng (7) }\end{array}$ & Peningkatan mutu SDM \\
\hline 3 & Peningkatan ketersediaan ikan dipusat produksi (1) & \multirow{3}{*}{$\begin{array}{l}\text { Perluasan jaringan bahan baku } \\
\text { dan jaringan pemasaran }\end{array}$} \\
\hline 4 & Penambahan suplier bahan bahan baku dan promosi produk (6) & \\
\hline 5 & Perbaikan mutu dan inovasi produk (8) & \\
\hline 6 & $\begin{array}{l}\text { Peningkatan koordinasi dan komunikasi dengan seluruh anggota } \\
\text { rantai pasok (2) }\end{array}$ & \multirow[t]{2}{*}{ Pembentukan kelembagaan } \\
\hline 7 & Pembentukan organisasi anggota rantai pasok (5) & \\
\hline 8 & Menjalin kemitraan perolehan biaya usaha (4) & $\begin{array}{l}\text { Menjalin kemitraan perolehan } \\
\text { biaya usaha }\end{array}$ \\
\hline
\end{tabular}

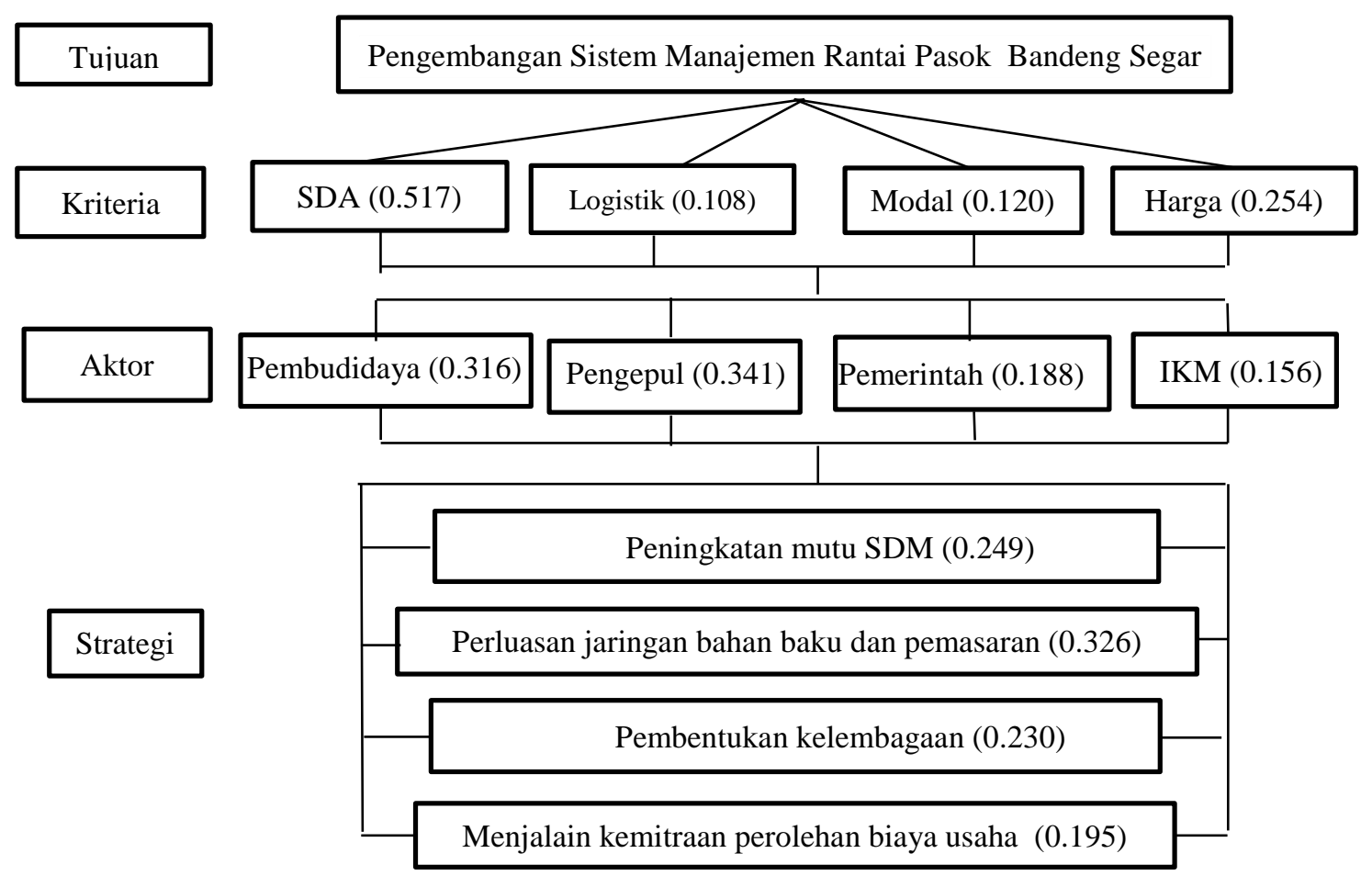

Gambar 4. Struktur hirarki strategi pengembangan sistem manajemen rantai pasok bandeng segar

\section{Analisis Kriteria}

Tabel 9 menyajikan hasil analisis kriteria yang paling berpengaruh terhadap pengembangan sistem manajemen rantai pasok bandeng segar di Kota Bekasi. Sumber daya alam atau potensi Kab. Karawang sebagai produsen bandeng menjadi sumber pendapatan bagi anggota rantai pasok bandeng segar di Kota Bekasi adalah kriteria paling dominan terhadap sistem manajemen rantai pasok bandeng segar di Kota Bekasi (skor 0.517).
Tabel 9. Hasil AHP prioritas kriteria

\begin{tabular}{lc}
\hline Kriteria & Skor \\
\hline Sumber daya alam & 0,517 \\
Logistik/sarpras & 0,108 \\
Harga & 0,254 \\
Modal & 0,120 \\
\hline
\end{tabular}

\section{Analisis Aktor}

Aktor yang paling berpengaruh terhadap rantai pasok adalah pengepul dengan skor 0,341 . Hasil analisis dicantumkan pada Tabel 10. 
Tabel 10. Analisis aktor rantai pasok

\begin{tabular}{ll}
\hline Kriteria & Skor \\
\hline Pembudidaya & 0,316 \\
Pengepul & 0,341 \\
Pemerintah & 0,188 \\
IKM Pengolah & 0,156 \\
\hline
\end{tabular}

Pengepul merupakan aktor yang berperan besar dalam pembelian dan pendistribusian bahan baku bagi IKM pengolah. Skor pengaruh setiap anggota rantai pasok terhadap kriteria dijabarkan pada Tabel 11.

Tabel 11. Analisis aktor terhadap kriteria

\begin{tabular}{lcccc}
\hline \multirow{2}{*}{ Aktor } & \multicolumn{4}{c}{ Kriteria } \\
\cline { 2 - 5 } & SDA & $\begin{array}{c}\text { Logistik/ } \\
\text { Sarpras }\end{array}$ & Harga & Modal \\
\hline Pembudidya & 0,514 & 0,199 & 0,246 & 0,293 \\
Pengepul & 0,087 & 0,151 & 0,401 & 0,174 \\
Pemerintah & 0,207 & 0,483 & 0,258 & 0,388 \\
IKM Pengolah & 0,191 & 0,167 & 0,095 & 0,145 \\
\hline
\end{tabular}

Berdasarkan Tabel 11, aktor yang paling berperan terhadap SDA adalah pembudidaya (skor 0,541), pembudidaya memproduksi bahan baku dengan memanfaatkan langsung potensi SDA Kab. Karawang. Pemerintah memegang peranan penting dalam penyediaan logistik/ sarpras (skor 0,483) dan fasilitasi peminjaman modal untuk seluruh anggota rantai pasok (skor 0,388). Pengepul mempunyai pengaruh dominan pada penentuan harga bahan baku (skor 0,401).

\section{Analisis dan Rekomendasi Prioritas Strategi}

Rekomendasi proiritas strategi untuk meningkatkan daya saing rantai pasok dicantumkan pada Tabel 12. Strategi utama yang perlu dilaksanakan pada pengembangan sistem manajemen rantai pasok bandeng segar adalah pembentukan jaringan baru (skor 0,326) diikuti dengan peningkatan kualitas SDM (skor 0,249).

Tabel 12. Analisis prioritas strategi

\begin{tabular}{ll}
\hline Kriteria & Skor \\
\hline Peningkatan kualitas SDM & 0,249 \\
Pembentukan jaringan baru & 0,326 \\
Pembentukan kelembagaan & 0,230 \\
Penguatan modal & 0,195 \\
\hline
\end{tabular}

Rantai pasok perlu menambah jaringan bahan baku. Penambahan pemasok akan menambah jumlah bahan baku IKM pengolah. Perluasan jaringan pemasaran produk akhir perlu dilakukan agar jumlah penjualan IKM pengolah meningkat. Peningkatan perolehan bahan baku dan penjualan produk akhir akan mempercepat dan menambah jumlah arus barang dari hulu ke hilir dan meningkatkan pendapatan rantai pasok. Untuk mencapai hal tersebut perlu peningkatan pengetahuan SDM agar dapat mengatasi gap analysis rantai pasok .

Setiap aktor berperan dalam peningkatan manajemen rantai pasok. Prioritas strategi untuk masing-masing aktor dijelaskan pada Tabel 13.

Tabel 13. Analisis dan rekomendasi prioritas strategi setiap aktor

\begin{tabular}{lcccc}
\hline \multirow{2}{*}{ Strategi } & $\begin{array}{c}\text { IKM } \\
\text { Pengolah }\end{array}$ & Pengepul & $\begin{array}{r}\text { Pembu- } \\
\text { didaya }\end{array}$ & $\begin{array}{r}\text { Peme- } \\
\text { rintah }\end{array}$ \\
\cline { 2 - 5 } $\begin{array}{l}\text { Peningkatan } \\
\text { kualitas SDM }\end{array}$ & 0,263 & 0,142 & 0,247 & 0,344 \\
\hline $\begin{array}{l}\text { Pembentukan } \\
\text { jaringan baru }\end{array}$ & 0,374 & 0,300 & 0,130 & 0,192 \\
\hline $\begin{array}{l}\text { Pembentukan } \\
\text { kelembagaan }\end{array}$ & 0,132 & 0,252 & 0,311 & 0,223 \\
\hline $\begin{array}{l}\text { Penguatan } \\
\text { modal }\end{array}$ & 0,232 & 0,307 & 0,312 & 0,241 \\
\hline
\end{tabular}

Berdasarkan Tabel 13, strategi utama bagi IKM pengolah adalah pembentukan jaringan bahan baku dan jaringan pasar yang baru (skor 0,374) dan peningkatan mutu SDM (skor 0,263). Pengepul perlu penguatan modal (skor 0,307) dan menjalin kerjasama dengan pembudidaya lain sebagai pemasok. Dengan modal yang cukup, pengepul dapat langsung memperoleh bandeng di TPHP tanpa harus bersaing dengan pengepul lain dan industri besar yang membutuhkan bandeng dengan jumlah lebih besar, karena sistem lelang dimulai dari jumlah pembelian terkecil. Strategi utama bagi pembudidaya sebagai aktor yang melaksanakan produksi bahan baku di bagian hulu rantai pasok adalah penguatan modal dan pembentukan kelembagaan dengan skor hampir sama (skor 0,312 dan 0,311). Peningkatan jumlah ketersediaan bahan baku di pusat produksi dapat dilakukan dengan penerapan teknologi produksi budidaya yang lebih efektif dengan biaya yang lebih besar. Melalui kelembagaan, pembudidaya bandeng Kab. Karawang dapat membentuk kelompok perolehan biaya usaha serta berbagi informasi untuk perolehan biaya usaha. Peningkatan mutu SDM (skor 0,344) merupakan strategi utama yang harus dilakukan pemerintah. Pengetahuan yang memadai merupakan modal utama rantai pasok untuk memanfaatkan kekuatan dan peluang, mengatasi kelemahan dan ancaman terhadap rantai pasok serta melakukan aktivitas sesuai standar yang ada. 


\section{KESIMPULAN}

Berdasarkan pembahasan kajian evaluasi dan pengembangan sistem manajemen rantai pasok bandeng segar di Kota Bekasi, Jawa Barat diperoleh simpulan bahwa seluruh aktivitas anggota rantai pasok tidak sesuai dengan standar yang ada. Strategi prioritas utama yang dapat dilakukan adalah pembentukan jaringan, yaitu jaringan perolehan bahan baku dan jaringan pemasaran. Strategi terbaik selanjutnya adalah peningkatan mutu SDM.

\section{DAFTAR PUSTAKA}

Anwar, S.N. 2011. Manajemen Rantai Pasokan (Supply Chain Management): Konsep dan Hakikat. J Dinamika Informatika. 3(2):1-7.

[BSN] Badan Standardisasi Nasional. 2009. SNI ISO 28000: 2009: Spesifikasi Sistem Manajemen Keamanan pada Rantai Pasokan. Jakarta (ID): BSN.

Nugraha, A.C. 2011. Analisis Rumusan Strategi Rantai Pasokan Minyak Akar Wangi di Kabupaten Garut, Jawa Barat. Fakultas Ekonomi dan Manajemen. Bogor (ID): Institut Pertanian Bogor.
[KKP] Kementerian Kelautan dan Perikanan. 2007. Keputusan Menteri Kelautan dan Perikanan Republik Indonesia Nomor 02 Tahun 2007 Tentang Cara Budidaya Ikan yang Baik. Jakarta (ID): KKP.

[KKP] Kementerian Kelautan dan Perikanan. 2014. KKP dalam Angka. Pusat Data dan Informasi Kementerian Kelautan dan Perikanan. Jakarta (ID): KKP.

Rangkuti, F. 2014. Analisis SWOT Teknik Membedah Kasus Bisnis. Jakarta. (ID): Gramedia Pustaka Utama.

Saaty, T.L. 1991. Pengambilan Keputusan bagi Para Pemimpin: Proses Hierarki Analitik untuk Pengambilan Keputusan dalam Situasi yang Kompleks. (Terjemahan: Decisioan Making for Leader: The Analitycal Hierarchy Process for Decision in Complex World). Jakarta (ID): Pustaka Binaman Presindo.

Setiawan, A., Marimin, Y. Arkeman, F. Udin. 2011. Studi Peningkatan Kinerja Manajemen Rantai Pasok Sayuran Dataran Tinggi di Jawa Barat. Agritech. 31(1): 60-70.

Yang, J. and P. Shi. 2002. Applying Analytical Hierarchy Process in Firms's Overall Performance Evaluation: A Case Study in China. International Journal of Business, 7(1): 29-4. 